\title{
Comunicação
}

\section{Tensão térmica e taxa de reação em um reator para gaseificação de biomassa do tipo concorrente ${ }^{1}$}

\author{
Samuel Martin², Jadir Nogueira da Silva ${ }^{3}$, Delly Oliveira Filho ${ }^{4}$, Sérgio M. Lopes Donzeles ${ }^{5}$, Fábio Luis Zanatta , \\ Reginaldo Rodrigues dos Santos ${ }^{7}$
}

\section{RESUMO}

A conversão da energia química da biomassa em outras formas de energia pode ser processada de diversas maneiras. Dentre essas, encontra-se a gaseificação, que utiliza reatores para conversão da biomassa em gás combustível. Para o dimensionamento de um gaseificador e seus constituintes, vários fatores devem ser levados em consideração, desde as características do combustível até as reais necessidades de energia térmica liberada. Especificamente no dimensionamento da grelha, alguns índices servem de referência, como a tensão térmica e a taxa de reação. Este trabalho teve como objetivos determinar a taxa de reação e a tensão térmica de uma grelha plana utilizada em um gaseificador bem como comparar os valores obtidos com aqueles recomendados para o dimensionamento de grelhas em fornalhas. Foi utilizado um gaseificador de biomassa de fluxo concorrente de pequena escala, ao qual foi acoplada uma câmara para combustão do gás produzido. O combustível utilizado foi toretes de eucalipto, em pedaços com diâmetro de 4 a $8 \mathrm{~cm}$ e comprimento de 10 a $20 \mathrm{~cm}$. Conclui-se que os índices de taxa de reação e tensão térmica encontrados podem ser utilizados como parâmetros para o dimensionamento de grelhas de gaseificadores de leito fixo.

Palavras-chave: Gaseificador, grelha, taxa de combustão.

\section{ABSTRACT}

\section{Thermal tension and reaction rate for a downdraft biomass gasifier}

The conversion of the biomass chemical energy into other energy forms may be processed in several ways. Among them, gasification uses reactors to convert biomass into combustible gas. For dimensioning the gasifier and its parts, several factors should be taken into account, from fuel characteristics to the real needs of the released thermal energy. Specifically to grate dimensioning, indices such as thermal tension and the reaction rate are used as reference. This study was conducted to determine the reaction rate and the thermal tension of a flat grate used in a gasifier, and to compare these values with the recommended dimensions for furnace grates. A small scale downdraft biomass gasifier coupled with a gas combustion chamber was used in the experiment. Eucalyptus firewood logs of 5-8 cm diameter and $10-20 \mathrm{~cm}$ length were used as fuel. It was concluded that the calculated indices of thermal tension and reaction rate can be used as parameters for grate design in fixed-bed gasifier.

Key words: Gasifier, grates, combustion rate

\footnotetext{
Recebido para publicação em setembro de 2007 e aprovado em março de 2010

1 Extraído da dissertação de mestrado do primeiro autor apresentada à Universidade Federal de Viçosa (UFV).

${ }^{2}$ Engenheiro-Agrônomo, Doutor. Departamento de Engenharia Agrícola (DEA), UFV, Av. Peter Henry Rolfs, s/n, centro, 36570-000, Viçosa, Minas Gerais, Brasil. samuel.martin@ufv.br

${ }^{3}$ Engenheiro Agrícola, Ph.D. DEA, UFV, Av. Peter Henry Rolfs, s/n, centro, 36570-000, Viçosa, Minas Gerais, Brasil. jadir@ufv.br

${ }^{4}$ Engenheiro Elétrico, Ph.D. DEA, UFV, Av. Peter Henry Rolfs, s/n, centro, 36570-000, Viçosa, Minas Gerais, Brasil. delly@ufv.br

${ }^{5}$ Engenheiro Agrícola, Doutor. EPAMIG/CTZM, Campus UFV, nº46 e 47, Vila Gianetti, 36571-000 Viçosa, Minas Gerais, Brasil. slopes@ufv.br

${ }^{6}$ Engenheiro Agrícola, Mestre. DEA, UFV, Av. Peter Henry Rolfs, s/n, centro, 36570-000, Viçosa, Minas Gerais, Brasil. fabio.zanatta@ufv.br

Engenheiro Agrícola, Doutor. DEA, UFV. Av. Peter Henry Rolfs, s/n, centro, 36570-000, Viçosa, Minas Gerais, Brasil. reginaldo.santos@ufv.br
} 


\section{INTRODUÇÃO}

Dentre as formas de aproveitamento de energia da biomassa (combustão - queima direta; pirólise; liquefação; fermentação; biodigestão e gaseificação), uma delas refere-se a sua transformação em uma mistura de gás combustível, por meio do uso de gaseificadores ou gasogênios, em substituição aos combustíveis derivados do petróleo ou para outros fins. Assim, a gaseificação da biomassa, associada à combustão dos gases produzidos, vem se revelando uma tecnologia capaz de gerar ar quente para fins agrícolas, como para secagem destes e também o aquecimento de instalações animais.

A gaseificação é definida como o processo de conversão da biomassa, ou de qualquer combustível sólido, em um gás energético, por meio da oxidação parcial a temperaturas elevadas. Nesse processo, reduz-se a quantidade de ar teórico ou estequiométrico para que ocorra a gaseificação, ou seja, em vez de se trabalhar com excesso de ar, como nos processos convencionais de combustão, utilizam-se valores entre 20 e $40 \%$ da quantidade teórica de ar. Essa conversão pode ser realizada em vários tipos de reatores, como de leito fixo e de leito fluidizado (Sánchez et al., 1997).

Em outras palavras, pode ser conceituada como um processo termoquímico de aproveitamento da biomassa, que consiste na obtenção de uma mistura de gases a partir do aquecimento de matérias-primas carbonáceas em condições controladas. Difere-se da combustão pelo fato de não utilizar a massa de ar teórica ou estequiométrica necessária para a oxidação completa do combustível, sendo essa fração de ar denominada de fator de ar, que é definido como a relação (ar/combustível)real/ (ar/ combustível)estequiométrica ou teórica.

O processo de gaseificação compreende quatro etapas: redução, combustão, pirólise e secagem. Cada uma ocorre em zonas relativamente separadas dentro do reator. Na zona de secagem, a temperatura é suficientemente baixa (menor que $200^{\circ} \mathrm{C}$ ) para evitar a decomposição da biomassa, porém suficientemente alta para eliminar sua umidade na forma de vapor (Cemig, 1986).

A zona de pirólise fica situada acima das zonas de oxidação e redução, que fornecem a energia necessária às reações de pirólise. Esta começa a ocorrer com temperaturas em torno de $200{ }^{\circ} \mathrm{C}$, quando a estrutura da biomassa começa a se decompor por ação térmica (Cemig, 1986). As reações de pirólise são exotérmicas, e a decomposição térmica ocorre entre 280 e $450^{\circ} \mathrm{C}$, acontecendo a decomposição dos carboidratos e a produção de alcatrão e ácidos leves (Sánchez et al., 1997).

A zona de oxidação é determinada pela posição da entrada do comburente no reator, cujo $\mathrm{O}_{2}$ é responsável pela queima de parte da matéria-prima, liberando energia térmica. A temperatura da zona de oxidação varia entre 800 e $1.200^{\circ} \mathrm{C}$, como resultado da reação exotérmica entre o carbono da matéria-prima e o $\mathrm{O}_{2}$. O gás quente da zona de oxidação passa, em seguida, à zona de redução, acima ou abaixo, dependendo do gaseificador. Nessa zona, deficiente em $\mathrm{O}_{2}$, ocorre a formação dos componentes combustíveis do gás (Cemig, 1986). A reação de Bourdouard passa a ser mais importante na faixa de temperatura de 800 a $900{ }^{\circ} \mathrm{C}$, ocorrendo em todo o leito, ao contrário das reações de formação de dióxido e monóxido de carbono, que só ocorrem obviamente com a presença de oxigênio, segundo Shaw \& Paterson (1978) citados por Sánchez et al. (1997).

As reações exotérmicas de oxidação (combustão) e as endotérmicas de redução envolvendo fase sólida e gasosa encontram-se na Tabela 1, conforme Sánchez et al. (1997). A distinção das diferentes zonas dentro do reator e sua conseqüente distribuição são dois fatos amplamente conhecidos pelos pesquisadores. Já quanto à espessura das camadas de cada zona e, principalmente, das zonas de oxidação e redução, esta é variável para cada caso e muito difícil de ser definida e determinada, em função das condições de operação. Para Mendes et al. (1998), a zona de oxidação pode variar de 10 a $15 \mathrm{~cm}$ de espessura, aproximadamente, e a zona de redução em torno de $20 \mathrm{~cm}$. Ponte Filho (1988), ao fazer citações sobre vários autores, mencionou que as alturas das zonas de oxidação e de redução dos gaseificadores de leito fixo são, em média, 15 e $80 \mathrm{~cm}$, respectivamente. Conforme levantamento feito por Bridgewater (1991) citado por Sánchez et al. (1997), na Tabela 2 observa-se que as características do gás produzido variam conforme o tipo do gaseificador.

Em revisão sobre o desenvolvimento e a comercialização de tecnologias de gaseificação da biomassa na China, Leung et al. (2004) citaram que a gaseificação da biomassa é tecnologia eficiente e avançada para extração

Tabela 1. Reações exotérmicas de oxidação e endotérmicas de redução de reatores

\begin{tabular}{lc}
\hline Reações heterogêneas gás-sólido & $\boldsymbol{\Delta H}\left(\mathbf{k J . m o l} \mathbf{- 1}^{\mathbf{1}}\right)$ \\
\hline Oxidação do carbono & $-110,6$ \\
$\mathrm{C}+1 / 2 \mathrm{O}_{2}=\mathrm{CO}$ & $-393,8$ \\
$\mathrm{C}+\mathrm{O}_{2}=\mathrm{CO}_{2}$ & \\
Reação de Bourdouad & 172,6 \\
$\mathrm{C}+\mathrm{CO}_{2}=2 \mathrm{CO}$ & \\
Reação de gás-d'água & 131,4 \\
$\mathrm{C}+\mathrm{H}_{2} \mathrm{O}=\mathrm{CO}+\mathrm{H}_{2}$ & \\
Formação de metano & $-74,9$ \\
$\mathrm{C}+2 \mathrm{H}_{2}=\mathrm{CH}$ & $\left.\mathbf{H ~ ( k J . m o l} \mathbf{1}^{-1}\right)$ \\
\hline Reações homogêneas (fase gasosa) & $-41,2$ \\
\hline $\mathrm{CO}+\mathrm{H}_{2} \mathrm{O}=\mathrm{CO}_{2}+\mathrm{H}_{2}$ & 201,9 \\
$\mathrm{CH}_{4}+\mathrm{H}_{2} \mathrm{O}=\mathrm{CO}^{2} 3 \mathrm{H}_{2}$ & \\
\hline
\end{tabular}

Rev. Ceres, Viçosa, v. 57, n.2, p. 168-174, mar/abr, 2010 
Tabela 2. Características do gás para diferentes tipos de gaseificadores de biomassa

\begin{tabular}{|c|c|c|c|c|c|c|c|}
\hline \multirow{2}{*}{ Gaseificador } & \multicolumn{5}{|c|}{$\begin{array}{l}\text { Composição do gás } \\
\text { \% volume (base seca) }\end{array}$} & \multirow{2}{*}{$\begin{array}{c}\text { PCS } \\
\text { kJ.Nm }{ }^{-3}\end{array}$} & \multirow{2}{*}{$\begin{array}{l}\text { Qualidade } \\
\text { do gás* }\end{array}$} \\
\hline & $\mathbf{H}_{2}$ & CO & $\mathrm{CO}_{2}$ & $\mathbf{C H}_{4}$ & $\mathbf{N}_{2}$ & & \\
\hline Leito fluidizado & 9 & 14 & 20 & 7 & 50 & 5.400 & Média \\
\hline Contracorrente & 11 & 24 & 9 & 3 & 53 & 5.500 & Pobre \\
\hline Concorrente & 17 & 21 & 13 & 11 & 48 & 5.700 & Boa \\
\hline
\end{tabular}

* Particulados e alcatrão.

Fonte: Bridgewater (1991) citado por Sánchez et al. (1997).

de energia e que esse processo tem recebido atenção crescente no mercado de energia. Dentre as suas utilizações citaram-se: equipamentos de secagem e caldeiras (em substituição ao carvão e ao óleo) e aplicação em cozinhas domésticas e na geração de energia elétrica.

Ao desenvolver uma investigação experimental de um gaseificador de biomassa de fluxo concorrente, utilizando como combustível pedaços de madeira, Zainal et al. (2002) utilizaram fator de ar entre 26 e 46\% (0,26 e 0,46 decimal).

Pathak et al. (2008) avaliaram a utilização de resíduos agrícolas e madeira em dois sistemas de gaseificação, de fluxos concorrentes, para aplicação térmica. Silva et al. (2000), testando um gaseificador/combustor a cavacos de lenha de fluxo contracorrente na secagem de café despolpado, concluíram que o uso dessa tecnologia é viável para essa aplicação. Em trabalho sobre gaseificação de biomassa com fluxo contracorrente para o aquecimento do ar na secagem de produtos agrícolas, Santos (2003) concluiu que o gaseificador atendeu aos propósitos esperados, disponibilizando ar quente e limpo, próprio para uso em secagem de produtos agrícolas, além do potencial de utilização em outras aplicações com boa eficiência térmica. Martin (2005) concluiu que a associação de um gaseificador de biomassa de fluxo concorrente a um combustor do gás produzido pode ser considerada uma alternativa para aquecimento de ar na secagem de produtos agrícolas.

As fornalhas ainda são os geradores de calor mais utilizados na geração de ar quente para secagem artificial dos produtos agrícolas. Em sua maioria, são constituídas por depósito de combustível, câmara de combustão, grelha, cinzeiro, entradas de ar ambiental e saída de ar quente. Quanto ao projeto de um gerador de calor, vários fatores devem ser levados em consideração, desde as características do combustível até as reais necessidades de energia térmica liberada.

Especificamente no dimensionamento da grelha, para que a ela permita a oxigenação suficiente do combustível, deve-se observar o escoamento das cinzas e se o material utilizado tenha resistência à corrosão térmica, suportando o calor liberado durante a combustão. Para tanto, al- guns índices estão disponíveis na literatura, como a taxa de combustão e a tensão térmica. Estes índices servem de referência e são calculados de modo a possibilitar comparações entre fornalhas, de acordo com o combustível utilizado, bem como servem de base para o dimensionamento de fornalhas.

A taxa de combustão $\left(\mathrm{N}_{\mathrm{c}}\right)$ é um índice que representa a massa de combustível queimada por unidade de área da grelha, por unidade de tempo, sendo utilizado para o dimensionamento de grelhas. Segundo Oliveira Filho (1986), na queima de lenha, palhas e bagaço de cana-deaçúcar em fornalha com grelha plana, carga manual e ar forçado, a taxa de combustão encontra-se na faixa de 150 a $300 \mathrm{~kg} \mathrm{~h}^{-1} \mathrm{~m}^{-2}$; enquanto Silva \& Silva (1998), em estudo de uma fornalha a carvão vegetal de fogo direto, obtiveram $54 \mathrm{~kg} \mathrm{~h}^{-1} \mathrm{~m}^{-2}$ para a fornalha testada. Gomes (1988) citou valores na faixa de 88 a $132 \mathrm{~kg} \mathrm{~h}^{-1} \mathrm{~m}^{-2}$ para uma fornalha a lenha de fogo direto e fluxo descendente. Em reatores para gaseificação de biomassa, além da ocorrência de combustão, verifica-se também a redução (compondo a chamada zona de reação), diferentemente de fornalhas nas quais ocorre apenas combustão. Portanto, neste trabalho, para que a terminologia seja a mais adequada, o termo taxa de reação $\left(\mathrm{N}_{\mathrm{r}}\right)$ foi utilizado para reatores de gaseificação de biomassa.

A tensão térmica da superfície da grelha $\left(Q_{a}\right)$ expressa a energia térmica liberada pelo combustível sobre a grelha. Segundo Lora \& Happ (1997), conforme a construção da fornalha e as características da biomassa utilizada, esses valores situam-se entre 400 e $2.100 \mathrm{~kW} \mathrm{~m}^{-2}$. Vlassov (2001) citou valores entre 1.100 e $1.600 \mathrm{~kW} \mathrm{~m}^{-2}$ para fornalhas com tiragem forçada e de $400 \mathrm{~kW} \mathrm{~m}^{-2}$ para fornalhas com tiragem natural.

Entretanto, no que se refere aos gaseificadores de biomassa de leito fixo, estes parâmetros não são encontrados na literatura. O presente trabalho teve como objetivos determinar a taxa de reação e a tensão térmica de uma grelha plana, utilizada em um gaseificador de biomassa de fluxo concorrente, tendo a lenha de eucalipto como combustível, bem como comparar os referidos valores com aqueles utilizados no dimensionamento de grelhas em fornalhas. 


\section{MATERIAL E MÉTODOS}

Para a determinação da taxa de reação e da tensão térmica da grelha plana, utilizou-se um gaseificador de biomassa de fluxo concorrente, construído e projetado por Martin et al. (2006).

Com base nos princípios e leis da termodinâmica e também conforme a disposição dos equipamentos utilizados no sistema realizou-se o balanço de massa e energia para o sistema (Figura 1). Com essa disposição e esquema, pode-se equacionar o balanço de massa conforme a equação 1 .

$\dot{\mathrm{m}}_{\mathrm{p}(\mathrm{a})}+\dot{\mathrm{m}}_{\mathrm{b}}+\dot{\mathrm{m}}_{\mathrm{p}(\mathrm{b})}+\dot{\mathrm{m}}_{\mathrm{cv}}+\dot{\mathrm{m}}_{\mathrm{s}(\mathrm{a})}+\dot{\mathrm{m}}_{\mathrm{s}(\mathrm{b})}=\dot{\mathrm{m}_{\mathrm{c}}}+\dot{\mathrm{m}}_{\mathrm{as}}$

em que $\mathrm{m}_{\mathrm{p}(\mathrm{a})}=$ vazão mássica de ar primário no reator, $\mathrm{kg} \cdot \mathrm{h}^{-1} ; \dot{m}_{\mathrm{b}}=$ vazão mássica de lenha, $\mathrm{kg} \cdot \mathrm{h}^{-1} ; \mathrm{m}_{\mathrm{p}(\mathrm{b})}=$ vazão mássica de ar primário no combustor, kg.h $\mathrm{h}^{-1} ; \mathrm{m}_{\mathrm{cv}}=$ vazão mássica de carvão, $\mathrm{kg} \cdot \mathrm{h}^{-1} ; \mathrm{m}_{\mathrm{s}(\mathrm{a})}=$ vazão mássica de ar secundário no combustor, kg.h $\mathrm{h}^{-1} ; \mathrm{m}_{\mathrm{s}(\mathrm{b})}$. vazão mássica de ar secundário no misturador, $\mathrm{kg} \cdot \mathrm{h}^{-1} ; \mathrm{m}_{\mathrm{c}}=$ vazão mássica das cinzas, kg.h ${ }^{-1}$; e $\dot{m}_{\text {as }}=$ vazão mássica do ar de secagem, kg.h $\mathrm{h}^{-1}$.

Quanto ao balanço de energia, desconsiderando-se a energia utilizada por dispositivos eletromecânicos, podese representá-lo pela Equação 2.

$$
\begin{aligned}
& \dot{m}_{p(a)} h_{u}+\dot{m}_{b} P C_{u}+\dot{m}_{p(b)} h_{u}+\dot{m}_{c v} P C_{c v}+\dot{m}_{s(a)} h_{u}+\dot{m}_{s(b)} h_{u}+\dot{Q_{v v c}}= \\
& \mathrm{m}_{\mathrm{c}} \mathrm{PCI}_{\mathrm{c}}+\mathrm{m}_{\mathrm{as}} \mathrm{h}_{\mathrm{u}} \text { as }
\end{aligned}
$$

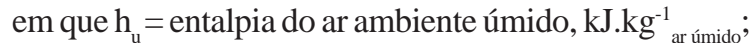

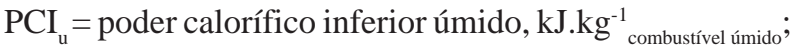
PCI $_{\mathrm{cv}}=$ poder calorífico inferior do carvão, kJ.kg$1_{\text {combustível seco; }}$ PCI $\mathrm{C}_{\mathrm{c}}=$ poder calorífico inferior das cinzas, ${\mathrm{kJ} . \mathrm{kg}^{-1} \text { combustível seco }}_{\text {e }} \mathrm{h}_{\mathrm{u} \mathrm{as}}=$ entalpia do ar de secagem úmido, $\mathrm{kJ} \mathrm{kg}^{-1}$

A partir da realização de cinco testes, foram determinados os parâmetros para o cálculo dos fatores estudados. Toretes de eucalipto com diâmetro de 4 a $8 \mathrm{~cm}$ e comprimento de 10 a $20 \mathrm{~cm}$ foram utilizados como combustível. O combustível encontrava-se exposto às condições ambientais locais e sob um abrigo, sendo então, amostrado e determinada sua umidade em estufa. A determinação do Poder Calorífico Superior (PCS) do combustível foi realizada, utilizando-se uma bomba calorimétrica. Com os dados do PCS calculou-se o Poder Calorífico Inferior do combustível úmido ( $\mathrm{PCI}_{\mathrm{u}}$ ), conforme Lopes (2002), para a composição elementar média citada por Vlassov (2001).

O reator apresentava formato cilíndrico, sendo construído de três manilhas de concreto revestidas, internamente, por tijolo refratário e encontrava-se sobre uma estrutura-base (cinzeiro). A grelha plana foi disposta internamente no reator, sendo a zona de reação (combustão e oxidação) delimitada em 0,46 m, conforme Martin et al. (2006). A grelha plana tinha diâmetro de 0,34 m e percentagem de área aberta de 49,71\%, e constituía-se de ferro maciço.

Na Figura 2 são apresentados detalhes da grelha plana usada na realização dos testes, enquanto na Figura 3 ilustra-se a sua disposição no reator. A área total de superfície da grelha equivale a $0,09079 \mathrm{~m}^{2}$.

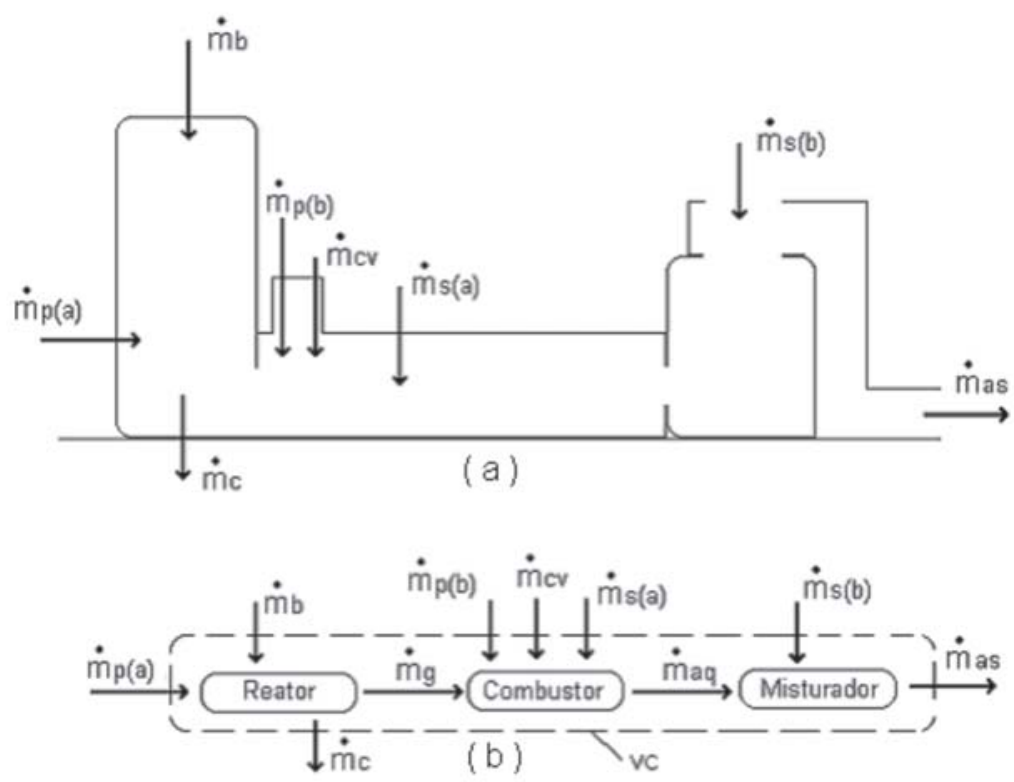

Figura 1. Disposições do sistema: (a) = ilustrado; e (b) = simplificado, especificando o volume de controle (VC). 
A Equação 3 representa o cálculo da taxa de combustão para fornalhas, sendo ainda utilizada na determinação da taxa de reação, no caso de gaseificadores de biomassa. Assim, considera-se $\mathrm{N}_{\mathrm{c}}=\mathrm{N}_{\mathrm{r}}$.

$\mathrm{N}_{\mathrm{c}}=\frac{\dot{\mathrm{m}}_{\mathrm{b}}}{\mathrm{A}_{\mathrm{t}}}$

em que $\mathrm{N}_{\mathrm{c}}=$ taxa de combustão, $\mathrm{kg} \cdot \mathrm{h}^{-1} \cdot \mathrm{m}^{-2} ; \mathrm{m}_{\mathrm{b}}=$ vazão mássica de biomassa, $\mathrm{kg}^{-1} \mathrm{~h}^{-1}$; $\mathrm{A}_{\mathrm{t}}=$ área total da grelha, $\mathrm{m}^{2}$.
A tensão térmica da superfície da grelha foi determinada de acordo com a Equação 4.

$$
\mathrm{Q}_{\mathrm{a}}=\frac{\dot{\mathrm{m}}_{\mathrm{b}} \mathrm{PCI}_{\mathrm{u}}}{3600 \mathrm{~A}_{\mathrm{t}}}
$$

em que $\mathrm{Q}_{\mathrm{a}}=$ tensão térmica da superfície da grelha, $\mathrm{kW} \cdot \mathrm{m}^{-2}$; e PCI $=$ poder calorífico inferior úmido do combustível, ${\mathrm{kJ} . \mathrm{kg}^{-1}}_{\text {combustivel úmido }}$.

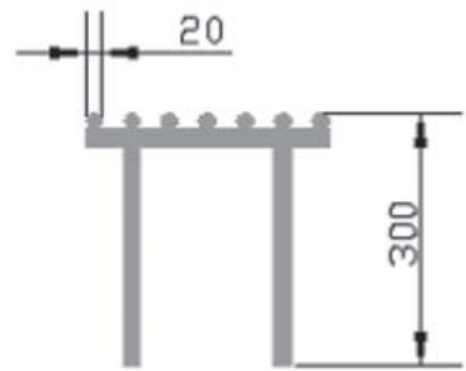

(b)

Figura 2. (a) Vista superior da grelha interna; e (b) vista lateral da grelha interna. Medidas em mm.

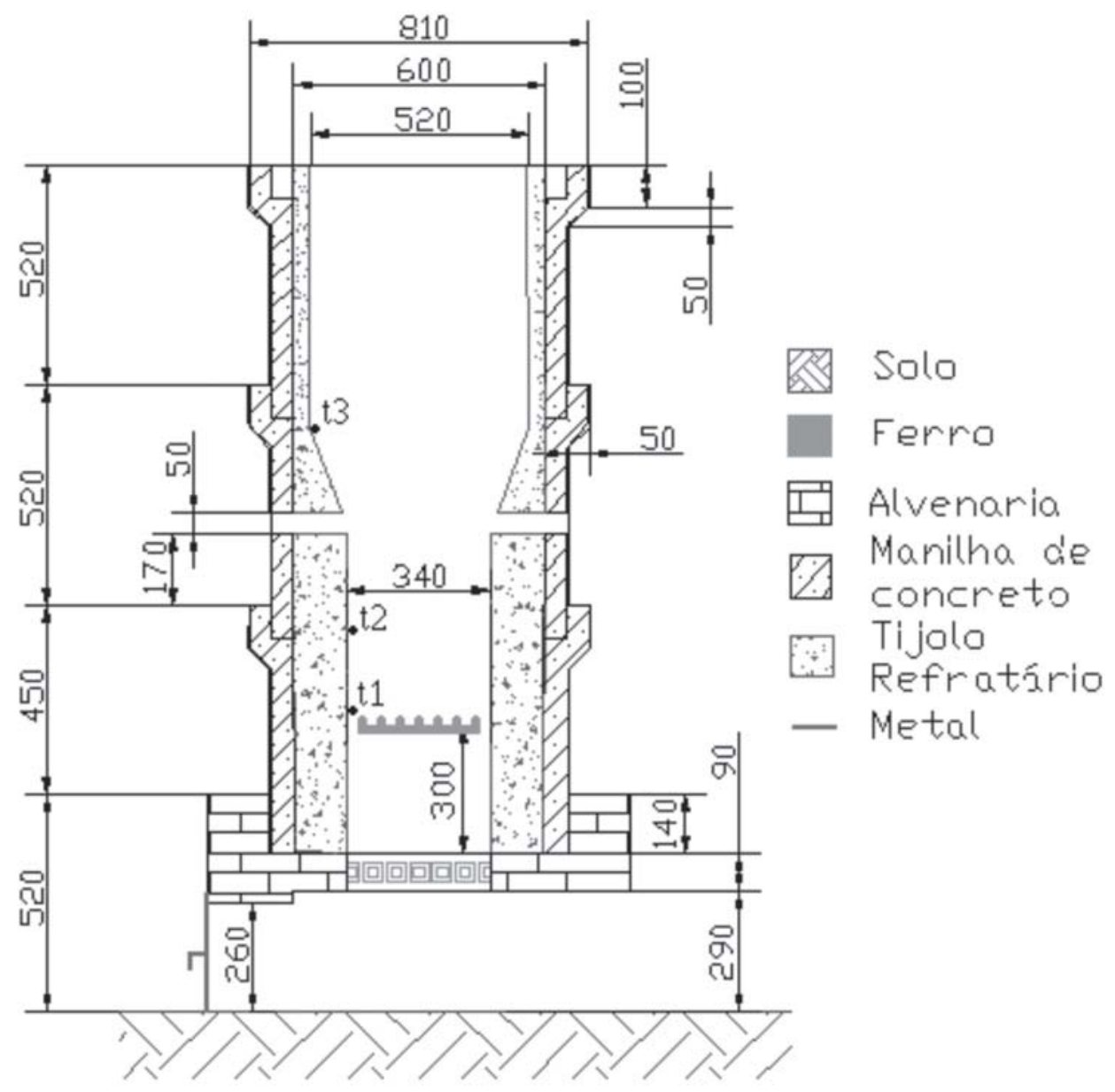

Figura 3. Corte longitudinal do reator com as suas respectivas medidas, em mm (t1 = termopar posicionado na zona de redução, a 10 mm de altura da grelha; t2 = termopar posicionado na zona de transição oxidação/redução, a 230 mm de altura da grelha; $\mathrm{t} 3=$ termopar posicionado na zona de secagem, à altura de $250 \mathrm{~mm}$ acima da entrada de ar primário do reator). 


\section{RESULTADOS E DISCUSSÃO}

O tempo médio de duração da gaseificação para os cinco testes realizados foi de 1,83 horas. O poder calorífico inferior $\left(\mathrm{PCI}_{\mathrm{u}}\right.$ ) médio foi de $15.258,74 \mathrm{~kJ} . \mathrm{kg}^{-1}$ para a madeira com teor de umidade média de $16,35 \%$, na base úmida. Na Tabela 3 observa-se o tempo de duração de cada teste, assim como os valores médios do fator de ar e de temperatura monitorados. Resultados semelhantes para a temperatura nas diferentes zonas do reator, apresentados neste trabalho, foram encontrados por Zainal et al. (2002) e Pathak et al. (2008).

Na Tabela 4 observam-se os valores da vazão mássica da lenha, da taxa de reação $\left(\mathrm{N}_{\mathrm{r}}\right)$ e da tensão térmica $\left(\mathrm{Q}_{\mathrm{a}}\right)$ constatados nos testes para o reator avaliado. Os valores encontrados para a taxa de reação nos cinco testes foram, em sua maioria, superiores aos da taxa de combustão para fornalhas. Isso pode ser atribuído ao fato de que nos reatores de gaseificação de biomassa a coluna de combustível sobre a grelha é maior do que aquela em fornalhas. Consequentemente ocorre maior consumo de combustível por unidade de área. Vale ressaltar que esse consumo não está, unicamente, relacionado à oxidação completa do com- bustível, mas também com as demais etapas da gaseificação. Em fornalhas, entretanto, o aumento da coluna de combustível pode implicar ineficiência da combustão, devido à formação de resistência à passagem do comburente, não permitindo a combustão completa desejada.

Para a tensão térmica sobre a grelha, os valores encontrados estão dentro do intervalo recomendado na literatura para o dimensionamento de grelhas em fornalhas. Valores maiores para a tensão térmica sobre a grelha poderiam ser esperados, pois no reator de gaseificação trabalha-se com uma coluna de combustível maior do que nas fornalhas. Entretanto, convém salientar que do processo de gaseificação é gerado no reator um gás de síntese, e que este gás que passa pela grelha e sai do reator é um gás combustível, ainda com potencial de liberar energia. Isto não ocorre em fornalhas, onde toda a energia do combustível é liberada sobre a grelha e o ar aquecido ao sair da fornalha não apresenta potencial combustível.

O dimensionamento de fornalhas e gaseificadores de biomassa necessitam dos balanços de energia - para calcular a biomassa necessária - e da determinação de índices que relacionam as quantidades de biomassa e as dimensões dos gaseificadores e das fornalhas.

Tabela 3. Resultados médios para os testes de gaseificação realizados

\begin{tabular}{lcccccc}
\hline \multirow{2}{*}{ Índice avaliado } & \multicolumn{5}{c}{ Teste } \\
\cline { 2 - 7 } & $\mathbf{1}$ & $\mathbf{2}$ & $\mathbf{3}$ & $\mathbf{4}$ & $\mathbf{5}$ & Média \\
\hline Tempo de gaseificação $(\mathrm{min})$ & 108,0 & 130,0 & 103,0 & 110,0 & 98,0 & 109,8 \\
Fator de ar $(\%)$ & 37,86 & 36,93 & 43,71 & 37,05 & 37,80 & 38,67 \\
Temperatura do ar ambiente $\left({ }^{\circ} \mathrm{C}\right)$ & 24,5 & 22,7 & 23,6 & 24,1 & 24,0 & 23,78 \\
Temperatura na zona de secagem $\left({ }^{\circ} \mathrm{C}\right)$ & 157,3 & 223,2 & 173,7 & 199,6 & 185,6 & 187,9 \\
Temperatura na zona de transição oxidação/redução $\left({ }^{\circ} \mathrm{C}\right)$ & 931,33 & 866,66 & 928,25 & 867,33 & 911,66 & 901,06 \\
Temperatura na zona de redução $\left({ }^{\circ} \mathrm{C}\right)$ & 919,66 & 718,66 & 889,00 & 906,66 & 902,33 & 867,26 \\
Temperatura do ar aquecido $\left({ }^{\circ} \mathrm{C}\right)$ & 102,2 & 74,4 & 97,5 & 104 & 107,4 & 97,1 \\
\hline
\end{tabular}

Tabela 4. Vazão mássica de biomassa $\left(\dot{\mathrm{m}}_{\mathrm{b}}\right)$, taxa de reação $\left(\mathrm{N}_{\mathrm{r}}\right)$ e tensão térmica $\left(\mathrm{Q}_{\mathrm{a}}\right)$ para os diferentes testes e média

\begin{tabular}{lcccccc}
\hline Índice avaliado & \multicolumn{7}{c}{ Teste } \\
\cline { 2 - 7 } & $\mathbf{1}$ & $\mathbf{2}$ & $\mathbf{3}$ & $\mathbf{4}$ & $\mathbf{5}$ & Média \\
\hline$\dot{\mathrm{m}}_{\mathrm{b}}\left(\mathrm{kg} \cdot \mathrm{h}^{-1}\right)^{*}$ & 30,00 & 23,84 & 26,47 & 28,35 & 31,00 & 27,93 \\
$\mathrm{~N}_{\mathrm{r}}\left(\mathrm{kg} \cdot \mathrm{h}^{-1} \cdot \mathrm{m}^{-2}\right)$ & 330 & 263 & 292 & 312 & 342 & 308 \\
$\mathrm{Q}_{\mathrm{a}}\left(\mathrm{kW} \cdot \mathrm{m}^{-2}\right)$ & 1.401 & 1.113 & 1.236 & 1.323 & 1.447 & 1.304 \\
\hline
\end{tabular}

* Umidade da lenha $=16,35 \%$ (b.u.)

\section{CONCLUSÕES}

Para o gaseificador de fluxo concorrente testado com lenha de eucalipto e a respectiva grelha plana conclui-se que:

Os índices de taxa de reação e tensão térmica encontrados podem ser utilizados como parâmetros importantes para o dimensionamento de grelhas de gaseificadores de biomassa de leito fixo.

O valor da taxa de reação média no gaseificador de biomassa de fluxo concorrente é $470 \%$ superior ao menor valor encontrado na literatura e muito semelhante ao maior, em comparação com a taxa de combustão de fornalhas.

A tensão térmica média sobre a grelha no gaseificador de biomassa de fluxo concorrente é $226 \%$ superior ao menor valor encontrado na literatura e $18,5 \%$ inferior ao maior, em comparação a resultados de tensão térmica encontrados para o dimensionamento de fornalhas.

\section{AGRADECIMENTOS}

À FAPEMIG, à CAPES e ao CNPq.

Rev. Ceres, Viçosa, v. 57, n.2, p. 168-174, mar/abr, 2010 


\section{REFERÊNCIAS}

Cemig - Companhia Energética de Minas Gerais (1986) Gaseificação de biomassa. Belo Horizonte, Divisão de Análise e Desenvolvimento Energético.

Gomes RAR (1988) Avaliação do desempenho de uma fornalha a lenha de fluxo descendente e com sistema de aquecimento direto. Dissertação de Mestrado. Universidade Federal de Viçosa, Viçosa, 56p.

Leung DYC, Yin XL \& Wu CZ (2004) A rewiew on the development and commercialization of biomass gasification technologies in China. Renewable and Sustainable Energy Reviews, 8:565-580.

Lopes RP (2002) Desenvolvimento de um sistema gerador de calor com opção para aquecimento direto e indireto do ar. Tese de Doutorado. Universidade Federal de Viçosa, Viçosa, 220p.

Lora ES \& Happ JF (1997) Classificação e balanço térmico das fornalhas para a combustão de biomassa. In: Cortez LAB \& Lora ES (Org.) Tecnologias de conversão energética da biomassa. Manaus, EDUA/EFEI. p.91-132.

Martin S (2005) Desenvolvimento de um gaseificador de biomassa de fluxo concorrente. Dissertação de Mestrado. Universidade Federal de Viçosa, Viçosa, 90p.

Martin S, Silva JN, Tinôco IFF, Vieira AC, Zanatta FL \& Melo LD (2006) Projeto e construção de um gaseificador de biomassa de fluxo concorrente. Engenharia na Agricultura, 4:238-249.

Mendes LM, Silva JR \& Trugilho PF (1998) Gaseificação de carvão vegetal ou madeira para geração de energia em pequena escala. Lavras, UFLA/FAEPE. 98p.
Oliveira Filho D (1986) Aquecimento de ar. Viçosa, Centreinar. 36p.

Pathak BS, Patel SR, Bhave AG, Broi PR, Sharma AM \& Shah NP (2008) Performance evaluation of an agricultural residue-based modular throat-type down-draft gasifier for thermal application. Biomass and Bioenergy, 32:72-77.

Ponte Filho F (1988) Gasificadores de leito fixo: análise e modelo para otimização de projetos e pesquisas. Brasília, Ed. do Centro Gráfico do Senado Federal. 165p.

Sánchez CG, Lora ES \& Gomes EO (1997) Gaseificação. In: Cortez LAB \& Lora ES (Org.) Tecnologias de conversão energética da biomassa. Manaus, EDUA/EFEI. p.255-347.

Santos IS (2003) Reator de gaseificação de biomassa em fluxo contracorrente. Dissertação de Mestrado. Universidade Federal de Viçosa, Viçosa, 76p.

Silva ID \& Silva JN (1998) Projeto, construção e teste de uma fornalha a carvão vegetal para secagem de café despolpado/ descascado. Revista Brasileira de Engenharia Agrícola e Ambiental, 3:301-307.

Silva JN, Saiki ET, Vilarinho MC \& Cardoso Sobrinho J (2000) Gaseificador/combustor a cavacos de lenha na secagem de café despolpado. In: $3^{\circ}$ Encontro Nacional de Energia no Meio Rural - AGRENER, Campinas. Anais. CD-ROM.

Vlassov D (2001) Combustíveis, combustão e câmaras de combustão. Curitiba, Editora da UFPR. 186p.

Zainal ZA, Rifau A, Quadir GA \& Seetharamu KN (2002) Experimental investigation of a downdraft biomass gasifier. Biomass and Bioenergy, 23:283-289. 